\title{
Preferences of patients undergoing hemodialysis - results from a questionnaire-based study with 4,518 patients
}

Inger Miriam Janssen'

Ansgar Gerhardus 2,3

Gero D von Gersdorff ${ }^{4}$

Conrad August Baldamus ${ }^{4}$

Mathias Schaller ${ }^{4}$

Claudia Barth ${ }^{5}$

Fueloep Scheibler ${ }^{6}$

'Department of Epidemiology and International Public Health, Bielefeld University, Bielefeld, Germany; ${ }^{2}$ Department for Health Services Research, University of Bremen, Bremen, Germany; ${ }^{3}$ Health Sciences Bremen, University of Bremen, Bremen, Germany; ${ }^{4}$ Department of Internal Medicine II, University Hospital of Cologne, Cologne, Germany; ${ }^{5} \mathrm{KfH}$ Kuratorium fuer Dialyse und Nierentransplantation e.V., Neu-Isenburg, Germany; ${ }^{6}$ Department of Non-Drug Interventions, Institute for Quality and Efficiency in Health Care, Cologne, Germany
Correspondence: Inger Miriam Janssen Department of Epidemiology and International Public Health, Bielefeld University, PO Box 10 0I 31,

3350I Bielefeld, Germany

Tel +4952I 1064455

Fax +4952I 1062987

Email inger.scheike@uni-bielefeld.de
This article was published in the following Dove Press journal:

Patient Preference and Adherence

26 June 2015

Number of times this article has been viewed

Background: Chronic kidney disease is an increasing health problem worldwide and in its final stage (stage V) can only be treated by renal replacement therapy, mostly hemodialysis. Hemodialysis has a major influence on the everyday life of patients and many patients report dissatisfaction with treatment. Little is known about which aspects of treatment are considered important by hemodialysis patients. The objective of this study was to rate the relative importance of different outcomes for hemodialysis patients and to analyze whether the relative importance differed among subgroups of patients.

Patients and methods: Within the framework of a yearly questionnaire which is distributed among patients receiving hemodialysis by the largest hemodialysis provider in Germany, we assessed the relative importance of 23 outcomes as rated on a discrete visual analog scale. Descriptive statistics were used to rank the outcomes. Subgroup analyses were performed using Mann-Whitney $U$ or Kruskal-Wallis tests.

Results: Questionnaires of 4,518 hemodialysis patients were included in the analysis. The three most important outcomes were safety of treatment, health-related quality of life, and satisfaction with care. Further important outcomes were hospital stays, accompanying symptoms, hemodialysis duration, and the improvement or preservation of a good emotional state. Age, profession, and education had the strongest influence on relevant differences of preferences for outcomes; no relevant influence of sex or comorbidity was observed.

Conclusion: Outcomes concerning the delivery or provision of care and aspects influencing quality of life are rated by patients to be at least as important as clinical outcomes. Many of the outcomes judged to be important by the patients are not regularly considered in research, evaluation studies, or quality programs.

Keywords: patient-centered outcomes, preference elicitation, chronic disease, patient-centered research, rating scale

\section{Introduction}

Chronic kidney disease (CKD) is an increasing health problem worldwide. ${ }^{1,2}$ The increase seems eminent when looking at just a few risk factors for CKD stage $\mathrm{V}$ : hypertension, increasing age, diabetes, or obesity. ${ }^{3}$ In Germany, the prevalence of dialysis patients increased from 769 to 808 cases per million between 2005 and $2006 .{ }^{4}$ A high prevalence of CKD is also observable in other European countries. ${ }^{5}$ In the US, the prevalence of patients with CKD increased from 290 to 1,738 cases per million between 1980 and 2009 and more than 870,000 patients were being treated in $2009 .{ }^{2}$ In stage $\mathrm{V}, \mathrm{CKD}$ can only be treated with renal replacement therapy, either dialysis or transplantation. ${ }^{6}$ About $65 \%$ of patients receive hemodialysis, $25 \%$ receive a kidney transplant, and $10 \%$ are treated by peritoneal dialysis. ${ }^{3}$ Patients treated with hemodialysis 
not only have a low health-related quality of life $^{7}$ but experience mortality rates of $15 \%-20 \%$ each year. ${ }^{8}$

Hemodialysis patients often feel dissatisfied with their treatment, and report how profound the impact of the disease and the treatment is on their lives. ${ }^{9-11}$ Beyond their immediate influence on the well-being of the patients, aspects such as patient perception of physician support or satisfaction with care affect the adherence and the cooperation of patients, ${ }^{5,12,13}$ which have been identified as major determinants of life expectancy and morbidity. ${ }^{10,14,15}$ Knowledge about attitudes and experiences of patients is essential to be able to better understand the reasons for nonadherence and dissatisfaction.

Over the past years, patient-centered care has gained importance, but researchers and practitioners have not fully incorporated patient-centered methods in their work..$^{16,17}$ A key aspect of patient-centered evaluation requires the involvement of patients in all aspects of research, including the selection of outcomes. Considering patient-reported outcomes is one way to incorporate important aspects for patients in research, even though other outcomes which are not patient reported can also be of relevance to patients. ${ }^{18}$ Many instruments have been used to assess the preferences of outcomes so far; among the most common are conjoint analysis methods, rating scales, or utility assessment methods. ${ }^{19}$ And although the measurement of patient-reported outcomes has gained importance over the past 10-15 years, still $75 \%$ of US drug labels do not include patient-reported outcomes. And even in those drug labels evaluating patient-reported outcomes, various aspects of the patient experience with care are not considered. ${ }^{20}$

There are indications of a divergence between the outcomes that are routinely measured in research and clinical practice and the preferences of patients with advanced kidney disease. ${ }^{9,21,22}$ The choice of outcomes used in the evaluation of treatments determines which information patients have available to decide which treatment they would prefer. The omission of outcomes which are relevant for patients can have direct consequences on their decision-making ability. ${ }^{20}$ So far, patient preferences have rarely been considered in choosing patient-relevant outcomes for research in the area of CKD stage $\mathrm{V} .{ }^{23}$

The objective of this study was to compare the relative importance of a large set of outcomes that may be of relevance to patients receiving a hemodialysis treatment for CKD. We also analyzed to what extent the relative importance of outcomes differed between predefined subgroups of patients.

\section{Methods}

\section{Identifying the outcomes and developing the questions}

To identify relevant outcomes, we held a group discussion with patients from a regional self-help group (Sektion Niederrhein, Interessengemeinschaft Niere e.v. [lower-Rhine area branch, the kidney interest group]). The group discussion took place during a regular group meeting which seven patients attended. The purpose of the study was explained to the patients and they were asked to talk about all hemodialysis treatment aspects they would consider important. Notes of the key issues were taken and condensed into 23 outcomes with the support of an additional patient who was not part of the group discussion. A pretest to assess the comprehensibility of the questions and the completeness of the outcomes used was conducted with five patients, who were not part of the self-help group discussion but were recruited in a hemodialysis clinic. The five patients were asked to comment on the 23 outcomes we established with input from the group discussion. We were especially interested in whether any relevant outcomes were missing and if they understood the meaning of the outcomes. All five patients were satisfied with the range of outcomes, reported that they understood the phrasing of the outcomes, and did not suggest further outcomes to be included.

We decided to use a simple rating scale in the form of a discrete visual analog scale (this scale resembles a Likert scale but differs slightly as it uses two phrased anchors, "not important" and "very important"). A review showed that rating scales can include a larger number of outcomes compared to more complex methods such as conjoint analysis. It also highlighted that patients find it relatively easy to answer these kinds of questions and the response rate of valid answers was higher than with more complex methods. ${ }^{19}$ A complete list of the 23 outcomes and their phrasing in the questionnaire (translated from German) is shown in Table 1. The discrete visual analog scale consisted of nine categories, ranging from not important (1) to very important (9), and was scored according to the Likert scale values.

\section{Population}

The Kuratorium fuer Dialyse und Nierentransplantation e.V. $(\mathrm{KfH})$ is the largest provider of hemodialysis in Germany. It comprises more than 200 units treating approximately 18,000 patients annually. As part of its quality assurance program, Quality in Nephrology (QiN), KfH sends a yearly questionnaire to its patients. ${ }^{24}$

Within the scope of a research collaboration with the $\mathrm{KfH}$, we were permitted to add our questions to the questionnaire 


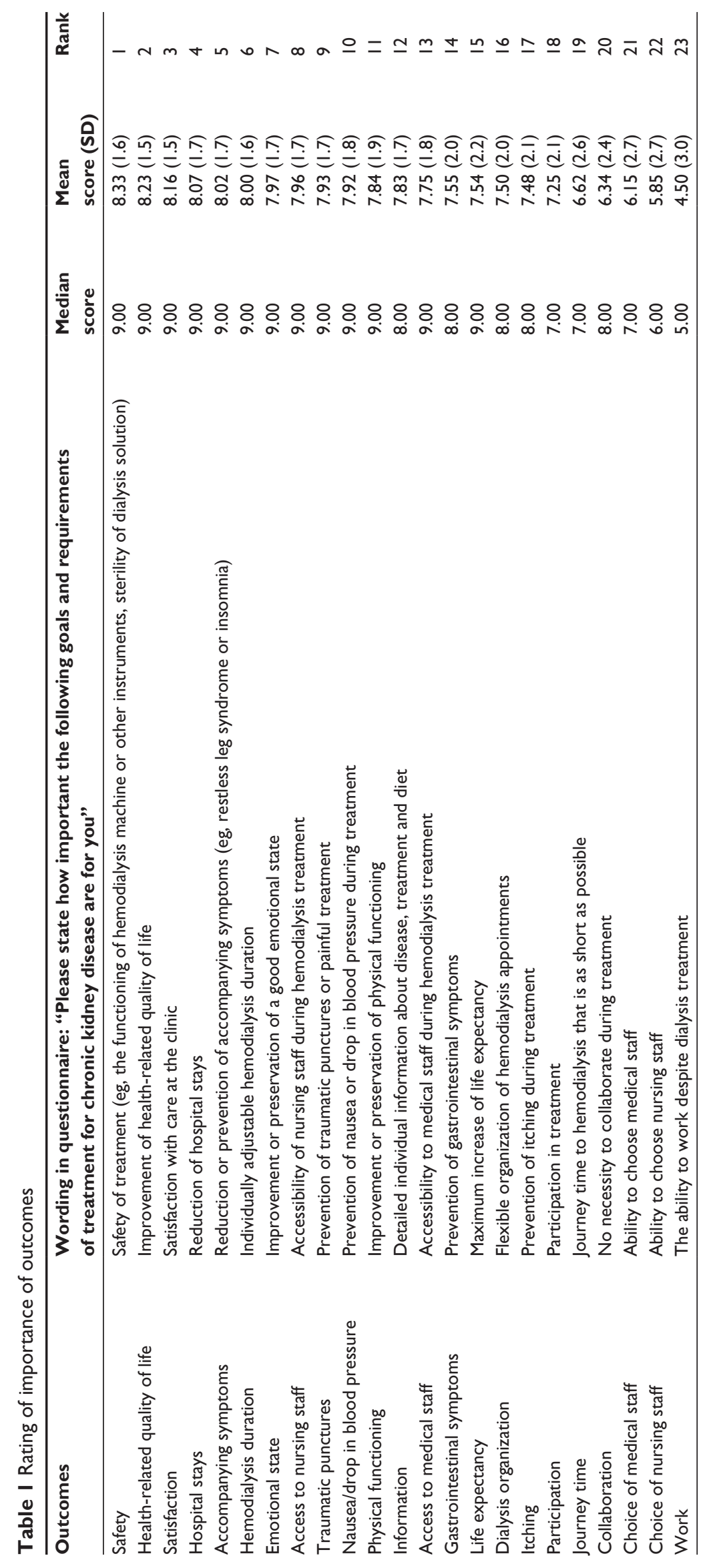


in the fourth quarter of 2008. The staff of each hemodialysis unit explained the purpose of the questionnaire, our questions, and the discrete visual analog scale to the patients, and handed them the questionnaire together with a consent form and a return envelope. The data of the entire questionnaire are collected within a quality assurance framework, and a specially assigned data protection commissioner ensures that patient data are dealt with correctly according to German data protection laws. Only data of patients who gave written informed consent were considered. The data of the questionnaire were all matched to additional data including information on sex, age, comorbidities, and time since start of hemodialysis, which was provided by an electronic patient record by research members of the quality assurance program QiN. Only those questionnaires where matching was possible were included in the analysis. As the individual centers do not keep count of how many questionnaires are distributed, it is not possible to calculate a precise response rate. The answers to our questions with the discrete visual analog scale and additional patient characteristic data were then provided by the research members of the QiN group to be analyzed.

\section{Data analysis}

Descriptive statistics (mean and median scores, standard deviations) were used to calculate the ratings of importance of outcomes. We ranked the importance of the 23 outcomes by mean scores. The results of the rating were also evaluated by constructing three summary scores for each outcome. The first score - designated "very important" - is the percentage of patients who selected the outcome as very important by assigning the value 7,8 , or 9 on the discrete visual analog scale. The second score - designated "somewhat important" is the percentage of patients who used the values 4,5 , or 6 on the scale to state their preference for the outcome. The third score - "not important" - is the percentage of patients who rated the outcome as being not important to them by choosing values 1,2 , or 3 on the scale.

Subgroups of patients were predefined by age (with age categories of 20 years each, 0-20, 21-40, etc), sex, comorbidity (diabetes mellitus), time since start of hemodialysis, education (highest school certificates), and profession (student, employed, unemployed, or retired). Subgroup analysis for the importance of each outcome was performed separately using Mann-Whitney $U$-tests for dichotomous data (sex, diabetes) and Kruskal-Wallis tests for categorical data (time since start of hemodialysis, age, education, and profession).
To assess the influence of a ceiling effect, which occurs when patients rate all outcomes as very important, we performed a sensitivity analysis. In this sensitivity analysis, all patients who rated all 23 outcomes with a value of 8 or higher were excluded from the analysis to investigate if the overall ratings of the outcomes would change in the remaining sample.

Data analysis was performed using PASW (Predictive Analytics SoftWare) Statistics 18 (SPSS Inc., Chicago, IL, USA). All analyses are based on response data; no responses were imputed.

\section{Results \\ Study population}

The survey was returned by 5,666 patients. Of these, 4,518 questionnaires could successfully be matched to additional data as provided by an electronic patient record. The calculation of a precise response rate was not possible, but with 18,000 patients that are treated in the participating hemodialysis centers, it was at least $31 \%$. The respondents did not, however, differ from the general population of patients with CKD stage $\mathrm{V}$ in Germany with regard to age, sex, and comorbidities. ${ }^{4}$ On average, patients were 66.6 years old (standard deviation: 5.3 ) and $58.4 \%$ of the patients were male. The majority of patients were retired (76\%) and only $10 \%$ were employed. Of those patients who specified their education, the majority $(51 \%)$ had a secondary level I school, vocational track certificate. On average, patients had been treated with hemodialysis for 4.4 years (standard deviation: 5.3) and $39.7 \%$ of the patients had diabetes. Detailed patient characteristics are presented in Table 2 .

\section{Ratings of outcomes}

The mean score of the 23 outcomes ranged between 4.50 and 8.33 (Table 1). Mean differences between the outcomes were rather small and the observed confidence intervals were overlapping. The three outcomes rated as most important were safety of treatment, health-related quality of life, and satisfaction with care. The outcomes rated fourth to tenth were related to treatment (individually adjustable hemodialysis duration, access to nursing staff during hemodialysis, reduction of traumatic punctures, or prevention of nausea/drop in blood pressure during treatment), to the reduction of hospital stays, to reduction or prevention of accompanying symptoms such as restless leg syndrome or insomnia, and to the improvement or preservation of a good emotional state. 
Table 2 Patient characteristics

\begin{tabular}{|c|c|}
\hline Patient characteristics & $\begin{array}{l}\text { Results } \\
(\mathrm{N}=4,5 \mid 8)\end{array}$ \\
\hline Age (years), mean (SD) & $66.6(13.9)$ \\
\hline \multicolumn{2}{|l|}{ Age categories (years), n (\%) } \\
\hline $0-20$ & $6(0.1)$ \\
\hline $21-40$ & $248(5.5)$ \\
\hline $4 I-60$ & $1,032(22.8)$ \\
\hline $6 I-80$ & $2,6 \mathrm{II}(57.8)$ \\
\hline $81-100$ & $621(13.7)$ \\
\hline Sex, male (\%) & $2,640(58.4)$ \\
\hline Diabetes & I,793 (39.7) \\
\hline Time on hemodialysis (years), mean (SD) & $4.4(5.3)$ \\
\hline \multicolumn{2}{|l|}{ Time on hemodialysis categories (years), n (\%) } \\
\hline $0-1$ & $\mathrm{I}, 446(32.0)$ \\
\hline $2-4$ & $1,516(33.6)$ \\
\hline $5-10$ & $989(21.9)$ \\
\hline$>10$ & $421(9.3)$ \\
\hline Not specified & $146(3.2)$ \\
\hline \multicolumn{2}{|l|}{ Occupation, n (\%) } \\
\hline Retired & $3,421(75.7)$ \\
\hline Employed & $435(9.6)$ \\
\hline Unemployed & $198(4.4)$ \\
\hline Student & $26(0.6)$ \\
\hline Not specified & $438(9.7)$ \\
\hline \multicolumn{2}{|l|}{ Education, ${ }^{\mathrm{a}} \mathrm{n}(\%)$} \\
\hline No school leaving certificate & $277(6.1)$ \\
\hline $\begin{array}{l}\text { Secondary level I school, vocational track } \\
\text { (Hauptschule, } 9 \text { years of education) }\end{array}$ & $2,3 \mid 5(5 \mid .2)$ \\
\hline $\begin{array}{l}\text { Secondary school level I certificate } \\
\text { (Mittlere Reife, } 10 \text { years of education) }\end{array}$ & $865(19.1)$ \\
\hline $\begin{array}{l}\text { General qualification for university entrance } \\
\text { (Abitur, } 12 \text { or } 13 \text { years of education) }\end{array}$ & $176(3.9)$ \\
\hline University degree & $337(7.5)$ \\
\hline Not specified & $548(12.1)$ \\
\hline
\end{tabular}

Note: according to the German school education system.

\section{Importance ratings of outcomes}

The percentages of patients ranking the outcomes as very important, somewhat important, and not important are presented in Figure 1. The outcomes safety, satisfaction, and health-related quality of life were rated as very important by more than $90 \%$ of patients. The ability to work was viewed as not important by more than $40 \%$ of patients and as very important only by approximately $30 \%$ of patients. The ability to choose nursing or medical staff was rated as very important by only around $50 \%$ of patients, and about $20 \%$ found these outcomes to be not important. The access to nursing staff was valued as very important by $90 \%$, and less than $4 \%$ of patients regarded this outcome as not important to them. Detailed individual information was valued as very important by more than $85 \%$, and as not important by less than $4 \%$. Life expectancy was rated very important by nearly $80 \%$, but more than $8 \%$ valued this outcome as not important.

\section{Ratings of outcomes by subgroups}

The most relevant statistically significant differences were observed in subgroups characterized by age, profession, or education (Table 3). Preferences only differed slightly between men and women and patients with or without diabetes. The age category $0-20$ years consisted of only six patients and was therefore not included in further subgroup analyses.

For all three subgroups (age, profession, and education), the largest difference in mean ranks as calculated either with Kruskal-Wallis or Mann-Whitney $U$-tests was observed in the outcome ability to work despite treatment. It was most important to younger patients, to students and the employed, and to those with higher education. No need to collaborate during treatment was most important to older patients, retirees, and - interestingly - those with a higher education. Access to medical staff was most important to older and retired patients and to those with a lower degree of education or with no school leaving certificate.

Age was the only subgroup in which we found a statistically significant and relevant influence on the subjective importance of the outcome life expectancy between different categories. A maximum increase in life expectancy was most important to younger patients. Also maintaining good health-related quality of life and good physical functioning was more important to younger patients than to older and to retired patients. The ability to choose the nursing staff was more important for those with lower education and least relevant to patients with a higher education.

\section{Sensitivity analysis}

A ceiling effect was observed in 107 patients who rated all 23 outcomes with 8 or higher. Ranking the aspects after exclusion of these patients did not substantially change the rank order of the remaining sample.

\section{Discussion}

To our knowledge, this study is the first to evaluate patient preferences for outcomes in CKD stage $\mathrm{V}$ treated with hemodialysis. One of the main findings is that traditional clinical outcomes are not clearly prioritized over outcomes related to the process of care.

The most important outcomes to patients were the safety of treatment, satisfaction with care at the clinic, and healthrelated quality of life. Patients were concerned about receiving good care, meaning safe treatment and satisfaction with care. In contrast, life expectancy was rated as less important than one would have expected. This may be due to the fact 


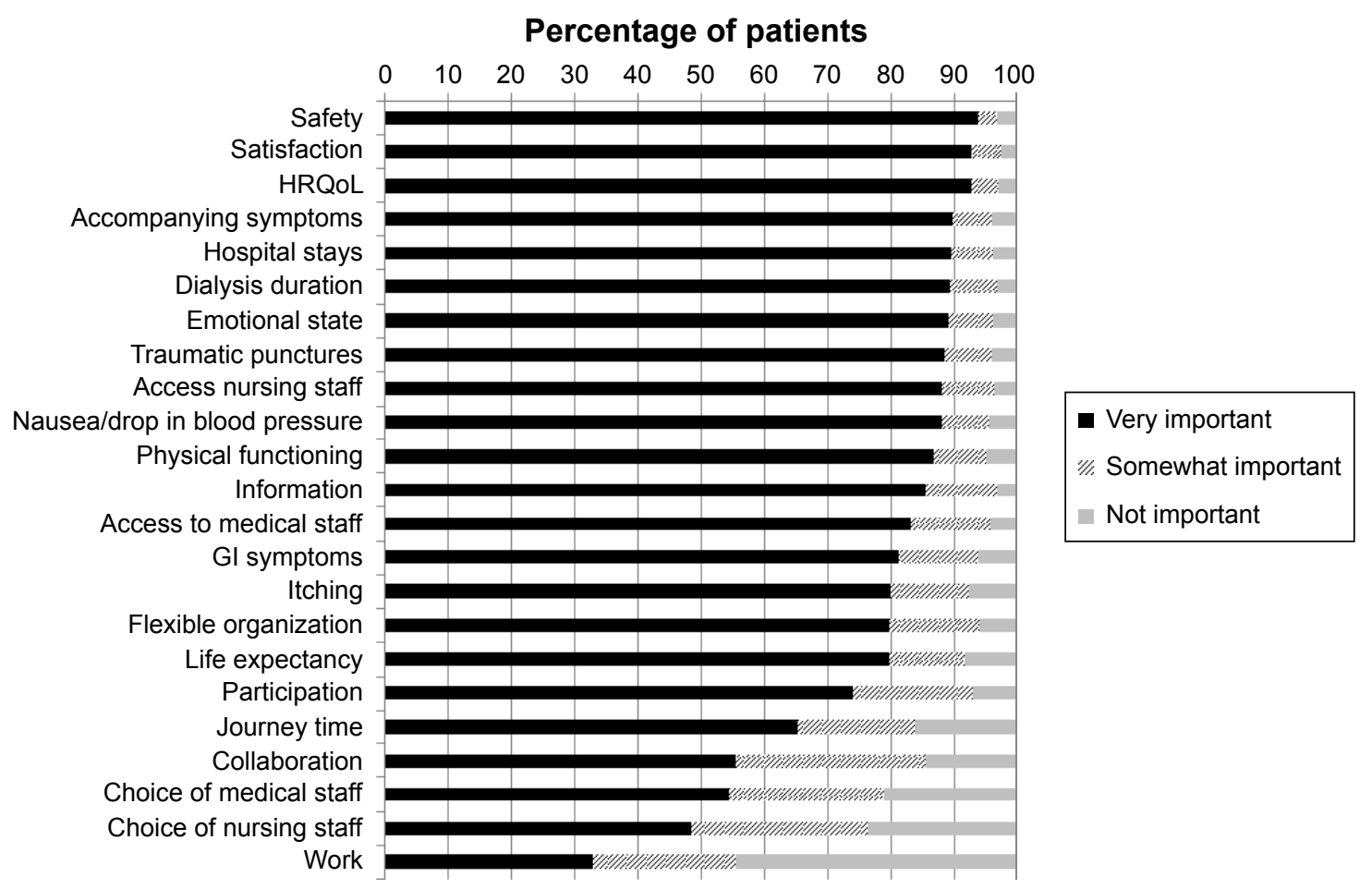

Figure I Frequency of importance of outcomes.

Abbreviations: $\mathrm{Gl}$, gastrointestinal; HRQoL, health-related quality of life.

that kidney failure has changed from an acute life-threatening event to a chronic condition.

Being on chronic hemodialysis treatment means that patients have to cope with a drastic change in everyday life. ${ }^{25}$ Consistent with that, the ten outcomes ranked as most important in our study were all related to how patients cope in their everyday life. Reducing accompanying symptoms, hospital stays, nausea, or drop in blood pressure during treatment were rated very important. Our findings are consistent with findings from other studies which show that hemodialysis treatment has a major impact on various domains of life..$^{10,11,26-29}$ The impact seems to be even larger in patients on hemodialysis compared to patients on peritoneal dialysis. ${ }^{10,11}$

The results of our study show that the possibility of individually adjusting the duration of hemodialysis was very important to patients. This suggests that patients want to have a more active role in their treatment, especially when it is time-consuming and impacts on their daily activities. This conclusion is supported by other studies which have shown similar results..$^{26,30,31}$ Research projects to optimize shared hemodialysis care have been undertaken and emphasize the importance patients place on their involvement in care. ${ }^{32-34}$

\section{Strengths and limitations}

The strength of this study is that a comprehensive set of outcomes was rated by a large group of more than 4,500 patients.
Although we hypothesized that all outcomes should be relevant to patients, as the set of 23 outcomes was chosen with the input of patients, the patients were able to rate which outcomes were most important to them. The findings of our study are relevant for all stakeholders involved in the treatment of chronic renal failure. There are also limitations.

Owing to the high number of outcomes, we decided to use a discrete visual analog scale. The disadvantage of this instrument is a ceiling effect. A sensitivity analysis, excluding the 107 patients who rated all 23 outcomes with 8 or higher, did not result in a different ranking of outcomes. However, in the remaining sample, we also observed high ratings for a majority of outcomes, indicating that our chosen outcomes were indeed very relevant to hemodialysis patients.

We were not able to estimate if patients had problems completing the questionnaire, because there was no record of how many questionnaires were distributed to the patients. However, rating scales are mostly perceived to be easily comprehensible for patients. ${ }^{19}$

The electronic patient record only provided data on diabetes as comorbidity; we were therefore not able to analyze the influence of other comorbidities on the preferences for specific outcomes. Furthermore, the rate of retired patients was very high in our sample. This has to be acknowledged when interpreting the results. A striking example is the rating of the ability to work outcome. This outcome was rated as very 


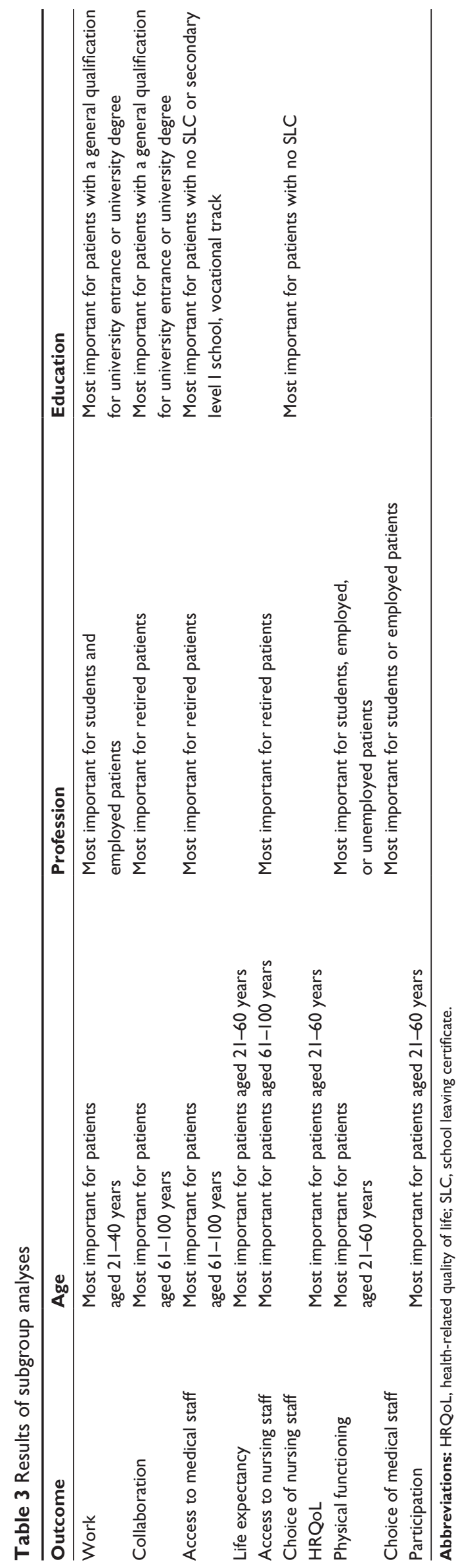

important by younger patients, but, unsurprisingly, as not so important for older patients who were already retired.

\section{Relevance to stakeholders}

Chronic hemodialysis treatment is a strenuous and timeconsuming treatment for patients. Medical professionals, researchers, and operators of hemodialysis clinics should be aware that aspects related to the delivery of hemodialysis treatment are very important to patients. This also impacts on adherence, which is a key factor for the success of treatment. ${ }^{35,36}$

\section{Conclusion}

The beneficial aspects of a hemodialysis treatment in reducing mortality and morbidity are not the only outcomes that matter to patients. Patients rate the absence of adverse effects of treatments, remaining in a good emotional state and good physical functioning, and the accessibility of nursing staff and individual information as important outcomes too. Many of the outcomes important to patients are currently not applied in research, evaluation studies, or quality programs by default. All stakeholders, including researchers, clinic operators, and health professionals, should be aware of the values patients place on outcomes and incorporate this information into their future work.

\section{Acknowledgments}

The authors want to thank all physicians, nurses, and technicians of the KfH kidney centers for their valuable efforts with data collection through the QiN registry system. We also want to thank all patients who supported us in identifying the outcomes and developing the questions. We acknowledge the support for the article processing charge from the Deutsche Forschungsgemeinschaft and the Open Access Publication Fund of Bielefeld University.

\section{Disclosure}

$\mathrm{CB}$ was the medical director of the $\mathrm{KfH}$ centers and in charge of the quality assurance system (QiN) at the time of the study. The authors report no other conflicts of interest in this work.

\section{References}

1. Levey AS, Atkins R, Coresh J, et al. Chronic kidney disease as a global public health problem: approaches and initiatives - a position statement from Kidney Disease Improving Global Outcomes. Kidney Int. 2007; 72:247-259.

2. National Kidney and Urologic Diseases Information Clearinghouse. Kidney Disease Statistics for the United States. Bethesda: U.S. Department of Health and Human Services, National Institutes of Health, National Institute of Diabetes and Digestive and Kidney Diseases; 2012. Available from: http://www.niddk.nih.gov/health-information/health-statistics/Documents/KU_Diseases_Stats_508.pdf. Accessed November 10, 2014. 
3. Abbasi MA, Chertow GM, Hall YN. End-stage renal disease. BMJ Clin Evid. 2010;2010.

4. Frei U, Schober-Halstenberg HJ. Nierenersatztherapie in Deutschland - Bericht über Dialysebehandlung und Nierentransplantation in Deutschland 2006/2007 [Renal replacement therapy in Germany - report on dialysis treatment and kidney transplantation in Germany 2006/2007]. Quasi Niere; 2008. Available from: http:// www.bundesverband-niere.de/fileadmin/user_upload/QuaSi-NiereBericht_2006-2007.pdf. Accessed November 10, 2014. German.

5. Zoccali C, Kramer A, Jager KJ. Chronic kidney disease and end-stage renal disease - a review produced to contribute to the report 'the status of health in the European union: towards a healthier Europe'. Clin Kidney J. 2010;3:213-224.

6. Eckardt KU, Coresh J, Devuyst O, et al. Evolving importance of kidney disease: from subspecialty to global health burden. Lancet. 2013; 382(9887):158-169.

7. Wyld M, Morton RL, Hayen A, Howard K, Webster AC. A systematic review and meta-analysis of utility-based quality of life in chronic kidney disease treatments. PLoS Med. 2012;9(9):e1001307.

8. US Renal Data System, USRDS 2013 Annual Data Report: Atlas of Chronic Kidney Disease and End-Stage Renal Disease in the United States. Bethesda: National Institutes of Health, National Institute of Diabetes and Digestive and Kidney Diseases; 2013. Available from: http://www.usrds.org/atlas13.aspx. Accessed November 10, 2014.

9. Palmer SC, de Berardis G, Craig JC, et al. Patient satisfaction with incentre haemodialysis care: an international survey. BMJ Open. 2014; 4(5):e005020.

10. Juergensen E, Wuerth D, Finkelstein SH, Juergensen PH, Bekui A, Finkelstein FO. Hemodialysis and peritoneal dialysis: patients' assessment of their satisfaction with therapy and the impact of the therapy on their lives. Clin J Am Soc Nephrol. 2006;1(6):1191-1196.

11. Wasserfallen JB, Moinat M, Halabi G, et al. Satisfaction of patients on chronic haemodialysis and peritoneal dialysis. Swiss Med Wkly. 2006; 136(13-14):210-217.

12. Krespi R, Bone M, Ahmad R, Worthington B, Salmon P. Haemodialysis patients' beliefs about renal failure and its treatment. Patient Educ Couns. 2004;53(2):189-196.

13. Tong A, Sainsbury P, Chadban S, et al. Patients' experiences and perspectives of living with CKD. Am J Kidney Dis. 2009;53(4): 689-700.

14. National Kidney Foundation. KDOQ1 clinical practice guidelines and clinical practice recommendations for 2006 updates: hemodialysis adequacy, peritoneal dialysis adequacy and vascular access. Am J Kidney Dis. 2006;48:S1-S322, 2006(suppl 1).

15. Kovac JA, Patel SS, Peterson RA, Kimmel PL. Patient satisfaction with care and behavioral compliance in end-stage renal disease patients treated with hemodialysis. Am J Kidney Dis. 2002;39(6): 1236-1244.

16. Patient-Centered Outcomes Research Institute (PCORI). The PCORI Methodology Report. Appendix A: Methodology Standards; 2013. Available from: http://www.pcori.org/assets/2013/11/PCORI-Methodology-Report-Appendix-A.pdf. Accessed November 10, 2014.

17. Gabriel SE, Normand SL. Getting the methods right - the foundation of patient-centered outcomes research. N Engl J Med. 2012;367(9): 787-790.

18. Eton DT, Elraiyah TA, Yost KJ, et al. A systematic review of patientreported measures of burden of treatment in three chronic diseases. Patient Relat Outcome Meas. 2013;4:7-20.

19. Janssen IM, Gerhardus A, Schröer-Günther MA, Scheibler F. A descriptive review on methods to prioritize outcomes in a health care context. Health Expect. Epub 2014 Aug 25.
20. Basch E. Beyond the FDA PRO guidance: steps toward integrating meaningful patient-reported outcomes into regulatory trials and US drug labels. Value Health. 2012;15(3):401-403.

21. Perrone RD, Coons SJ, Cavanaugh K, Finkelstein F, Meyer KB. Patientreported outcomes in clinical trials of CKD-related therapies: report of a symposium sponsored by the national kidney foundation and the U.S. Food and Drug Administration. Am J Kidney Dis. 2013;62(6): 1046-1057.

22. Morton RL, Snelling P, Webster AC, et al. Dialysis modality preference of patients with CKD and family caregivers: a discrete-choice study. Am J Kidney Dis. 2012;60(1):102-111.

23. Draborg E, Andersen CK. Recommendations in health technology assessments worldwide. Int $J$ Technol Assess Health Care. 2006; 22(2):155-160.

24. Stoffel MP, Barth C, Lauterbach KW, Baldamus CA. Evidence-based medical quality management in dialysis - Part I: Routine implementation of QiN, a German quality management system. Clin Nephrol. 2004; 62(3):208-218.

25. Ortiz A, Covic A, Fliser D, et al; Board of the EURECA-m Working Group of ERA-EDTA. Epidemiology, contributors to, and clinical trials of mortality risk in chronic kidney failure. Lancet. 2014;383(9931): 1831-1843.

26. Finnegan-John J, Thomas VJ. The psychosocial experience of patients with end-stage renal disease and its impact on quality of life: findings from a needs assessment to shape a service. ISRN Nephrol. 2013; 2013: 308986.

27. Anees M, Hameed F, Mumtaz A, Ibrahim M, Saeed Khan MN. Dialysisrelated factors affecting quality of life in patients on hemodialysis. Iran J Kidney Dis. 2011;5(1):9-14.

28. Morton RL, Tong A, Webster AC, Snelling P, Howard K. Characteristics of dialysis important to patients and family caregivers: a mixed methods approach. Nephrol Dial Transplant. 2011;26(12):4038-4046.

29. Morton RL, Snelling P, Webster AC, et al. Factors influencing patient choice of dialysis versus conservative care to treat end-stage kidney disease. CMAJ. 2012;184(5):E277-E283.

30. Griva K, Mooppil N, Seet P, Krishnan DS, James H, Newman SP. The NKF-NUS hemodialysis trial protocol - a randomized controlled trial to determine the effectiveness of a self management intervention for hemodialysis patients. BMC Nephrol. 2011;12:4.

31. Morton RL, Devitt J, Howard K, Anderson K, Snelling P, Cass A. Patient views about treatment of stage 5 CKD: a qualitative analysis of semistructured interviews. Am J Kidney Dis. 2010;55(3): 431-440.

32. Glidewell L, Boocock S, Pine K, et al; Yorkshire and Humber Shared Haemodialysis Care team. Using behavioural theories to optimise shared haemodialysis care: a qualitative intervention development study of patient and professional experience. Implement Sci. 2013;8:118.

33. Domecq JP, Prutsky G, Elraiyah T, et al. Patient engagement in research: a systematic review. BMC Health Serv Res. 2014;14:89.

34. Karimi Moonaghi H, Hasanzadeh F, Shamsoddini S, EmamimoghadamZ, Ebrahimzadeh S. A comparison of face to face and video-based education on attitude related to diet and fluids: adherence in hemodialysis patients. Iran J Nurs Midwifery Res. 2012;17(5):360-364.

35. Costantini L. Compliance, adherence, and self-management: is a paradigm shift possible for chronic kidney disease clients? CANNT J. 2006;16(4):22-26.

36. Kammerer J, Garry G, Hartigan M, Carter B, Erlich L. Adherence in patients on dialysis: strategies for success. Nephrol Nurs J. 2007;34(5): 479-486. 
Patient Preference and Adherence

Dovepress

\section{Publish your work in this journal}

Patient Preference and Adherence is an international, peer-reviewed, open access journal that focuses on the growing importance of patient preference and adherence throughout the therapeutic continuum. Patient satisfaction, acceptability, quality of life, compliance, persistence and their role in developing new therapeutic modalities and compounds to optimize

Submit your manuscript here: http://www.dovepress.com/patient-preference-and-adherence-journa clinical outcomes for existing disease states are major areas of interest for the journal. This journal has been accepted for indexing on PubMed Central The manuscript management system is completely online and includes a very quick and fair peer-review system, which is all easy to use. Visit http://www. dovepress.com/testimonials.php to read real quotes from published authors. 